\title{
Evaluation of umbilical cord arterial blood gas analysis in gestational diabetes mellitus
}

\author{
Geena Augustine1, Ranjith Sreedharan ${ }^{2, *}$, Ursula Sampson ${ }^{3}$, Jithesh T.K. ${ }^{4}$, R. Manikumar ${ }^{5}$ \\ ${ }^{1}$ Assistant Professor, Dept. of Anatomy, MES Medical College, Perinthalmanna, Kerala, ${ }^{2}$ Professor, Dept. of Anatomy, Jubilee \\ Mission Medical College \& Research Institute, Thrissur, Kerala, ${ }^{3}$ Professor, Dept. of Biochemistry, Meenakshi Medical College \\ and Research Institute, Chennai, Tamil Nadu, ${ }^{4}$ Associate Professor, ${ }^{5}$ Research Supervisor, ${ }^{4}$ Dept. of Biochemistry, ${ }^{5}$ Dept. of \\ Central Research, MES Medical College, Perinthalmanna, Kerala, India
}

*Corresponding Author: Ranjith Sreedharan

Email: drranjithanatomy@ gmail.com

Received: $7^{\text {th }}$ September, 2018

Accepted: $20^{\text {th }}$ September, 2018

\begin{abstract}
Gestational diabetes mellitus (GDM) represents glucose levels in the high end of the population distribution during pregnancy. GDM carries a high risk of adverse outcomes such as perinatal outcomes and a longer-term risk of obesity and glucose intolerance in offspring. Mothers with GDM have an excess of hypertensive disorders during pregnancy and a high risk of diabetes mellitus after that. This study aimed to evaluatethe influence of hypoxia status, haematological parameters, cord blood lactate, and birth weight of infants on GDM and its complications. The study was conducted on 100 pregnant women having Gestational Diabetes Mellitus (GDM), and the control population consists of 50 normal pregnancies. Samples included in this study were foetal cord blood and maternal blood. Parameters such as blood gases, lactate, haemoglobin, RBC count, red cell indices, and fetal birth weight were determined. No suggestive changes were found in $\mathrm{pH}$ of GDM neonates when compared to the healthy foetus.GDM offspring, when compared to the normal, showed a significant decrease in $\mathrm{pO}_{2}$ and $\mathrm{pCO}_{2} . \mathrm{A}$ relative reduction in $\mathrm{O} 2$ saturation and $\mathrm{O} 2$ content in GDM foetus when compared to a healthyfoetus. Lactate level is significantly increased in GDM neonates when correlated to the control group. There is a striking change in haemoglobin, RBC count, total WBC count, MCV and MCH in GDM. The results also suggest a correlation of cord blood $\mathrm{Hb}$, cord blood PCV and Cord blood pO2 with the birth weight of infants. Lower oxygen saturation and oxygen content and increased lactate concentrations in offspring of GDM mothers indeed emulate intensified fetal metabolism as an outcome of hyperglycaemia and hyperinsulinemia, and therefore these fetuses demandconstant supervision at term and during delivery.
\end{abstract}

Keywords: Gestational diabetes mellitus, Umbilical arterial cord blood, Hypoxic-ischemic event.

\section{Introduction}

Gestational diabetes mellitus (GDM) is defined as impaired glucose tolerance with onset or first recognition during pregnancy. The incidence of GDM varies between populations ranging from $1.7 \%$ to $11.6 \% .^{1}$ According to the International Diabetes Federation, 21 million pregnancies were affected by diabetes during the year 2013. India has the second largest number of subjects having diabetes in the world (62.4 million), and this number is expected to reach 100 million by the year $2030 .^{2}$

Women with Gestational uncontrolled diabetes can lead to a huge baby that can increase the risk of birth injury, hypoxia, brain ischemia, brachial plexus injury, Erb's palsy or shoulder dystocia and cerebral palsy. Complications for the fetal growth are macrosomia, hyperbilirubinemia, respiratory distress syndrome, polycythemia, neonatal jaundice and preterm birth. Not only that, infants resolved to maternal diabetes had an elevated risk of diabetes and obesity in infancy and adolescence. $^{3}$

The evolving foetus depends on the mother for the placental interchange of oxygen and carbon dioxide. This in turn, depends on sufficient maternal blood gas concentrations, uterine blood supply, and placental and foetal gas exchange. Fetal hyperglycemia and subsequent hyperinsulinemia stimulate aerobic metabolism that may further intensify the fetal oxygen demand. ${ }^{4}$ On the occasion of anoxic/hypoxic-ischemic events, Hypoxic Ischemic Encephalopathy (HIE) occurs which may lead to permanent brain damage to the baby. The result of a hypoxic-ischemic encephalopathy condition often leads to cerebral palsy or seizure disorders. ${ }^{5}$

The most elegant approach to asses anoxic or a hypoxic-ischemic event is the umbilical cord arterial blood analysis is that as it arrives from the baby. The most unbiased way of evaluating fetal metabolic condition at birth is the Umbilical cord arterial blood analysis. This appraisement soon after delivery conveys the newborn's acid-base status. ${ }^{6}$ All high-risk deliveries are now suggested to evaluate the cord blood analysis by both the British and American Colleges of Obstetrics and Gynaecology. Hence the present study was carried out to find the influence of hypoxia status, haematological parameters, cord blood lactate, and birth weight on GDM and its complications.

\section{Materials and Methods}

A case-control study was conducted at MES Medical College Perinthalmanna, Kerala. The test populations were the pregnant women who attended the 
Gynecology \& Obstetrics department of MES Medical College, who has been diagnosed to have GDM.

Inclusion Criteria: Age group between 19 to 38 years and both under diet control and insulin therapy are included in the test population. The control group will be the pregnant women with normal glucose level and uncomplicated pregnancy.

Exclusion Criteria: Pregnant women with overt diabetes mellitus, with unknown glycemic status and deliveries before the period of viability of fetus will be excluded.

Study Design: Test population consists of 100 pregnant women with GDM and control population consists of 50 normal pregnancies. The study was performed after obtaining clearance from the institutional ethics committee. Before the collection of samples, informed consent was obtained. The screening test for the GDM was carried out according to the WHO recommended protocol which is followed in the MES Medical College, Perinthalmanna. A maternal venous blood sample was collected before delivery and transferred into EDTA bottles. A segment of umbilical cord was double clamped immediately after delivery and before first breath, excised. Umbilical arterial blood samples were taken in heparinized syringes and EDTA tubes. The heparinised samples are analyzed by ABG analyzer (I-stat) within 30 minutes after birth for $\mathrm{pH}, \mathrm{pO}$,
pCO2, and lactate. The EDTA samples of maternal and cord blood were analysed for haematological parameters like haemoglobin (Hb), RBC count and Red cell indices.

\section{Statistical Analysis}

Statistical analysis was done by entering the mean and SD values in MYSTAT 12 (SYSTAT) software. The results were expressed as a mean and standard deviation. The $\mathrm{P}$ value was used to compare the parameters between the two groups. A un-paired t-test was selected for finding the $\mathrm{p}$-value. The $\mathrm{P}$ value less than 0.05 are considered as significant.

\section{Results}

The results and findings are given in tables and figures. No suggestive changes were found in $\mathrm{pH}$ of GDM neonates when compared to the healthy fetus. GDM offspring, when compared to the normal, showed a significant decrease in $\mathrm{pO} 2$ and $\mathrm{pCO} 2$. A relevant reduction in $\mathrm{O} 2$ saturation and $\mathrm{O} 2$ content in GDM foetus when compared to a normal embryo (Table 1). The present study indicates that lactate level is significantly increased in GDM neonates when compared to the control group.

Table 1: Respiratory gases, acid-base balance in normal (control) and GDM (test)

\begin{tabular}{|l|c|c|c|c|}
\hline \multicolumn{1}{|c|}{ Parameters } & Control $(\mathbf{n = 5 0})$ & Test $(\mathbf{n = 1 0 0})$ & $\mathbf{t}$ & $\mathbf{p}$ \\
\hline C.B. pH & $7.26 \pm 0.07$ & $7.26 \pm 0.06$ & -0.037 & 0.971 \\
\hline C.B. pCO2 $(\mathrm{mmHg})$ & $50.55 \pm 3.98$ & $52.17 \pm 4.64$ & -2.118 & $<0.05^{*}$ \\
\hline C.B. pO2 $(\mathrm{mmHg})$ & $27.04 \pm 2.5$ & $23.73 \pm 2.15$ & 8.382 & $<0.01^{* *}$ \\
\hline C.B. O2 Sat $(\%)$ & $66.37 \pm 3.96$ & $47.01 \pm 7.08$ & 17.955 & $<0.01^{* *}$ \\
\hline C.B. Lactate $(\mathrm{mmol} / \mathrm{L})$ & $2.05 \pm 0.74$ & $2.72 \pm 0.58$ & -6.005 & $<0.01^{* *}$ \\
\hline Al & &
\end{tabular}

All Values are mean \pm Standard Deviation. $\mathrm{n}=$ Total Number of subjects. The statistical test used is $\mathrm{t}-$ test. *Significant at $\mathrm{p}<0.05$ and $* *$ Significant at $\mathrm{p}<0.01$.

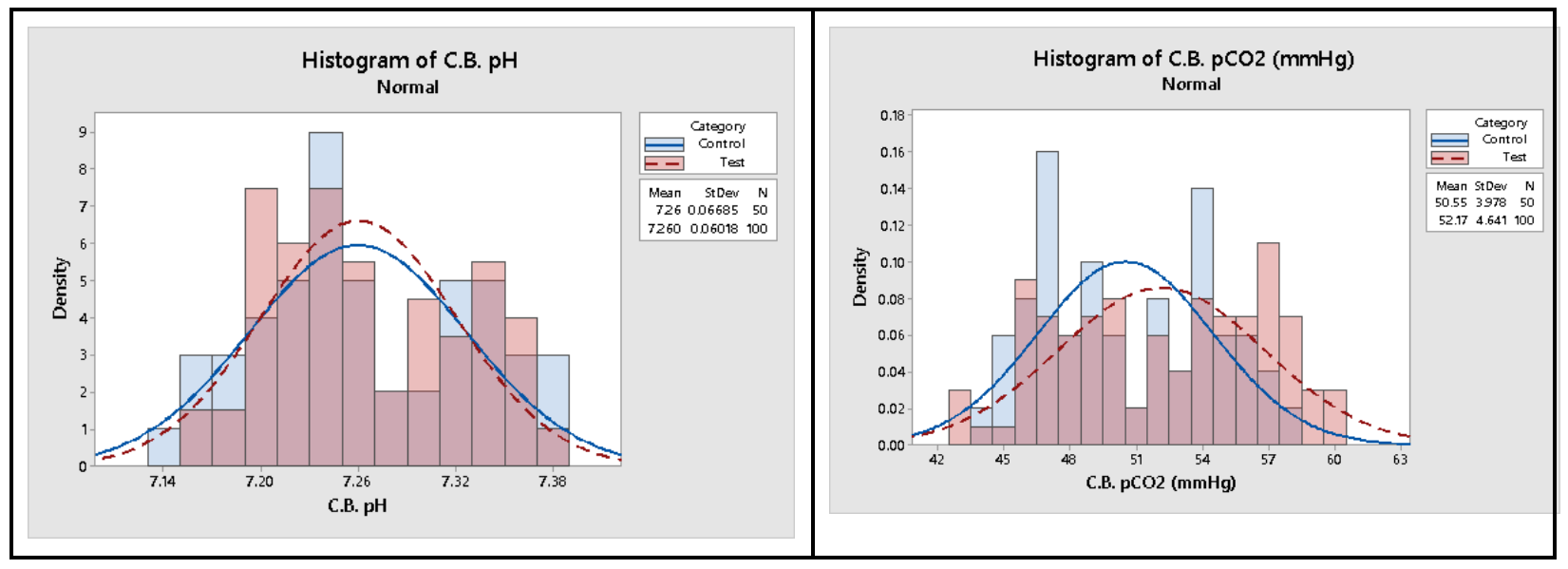




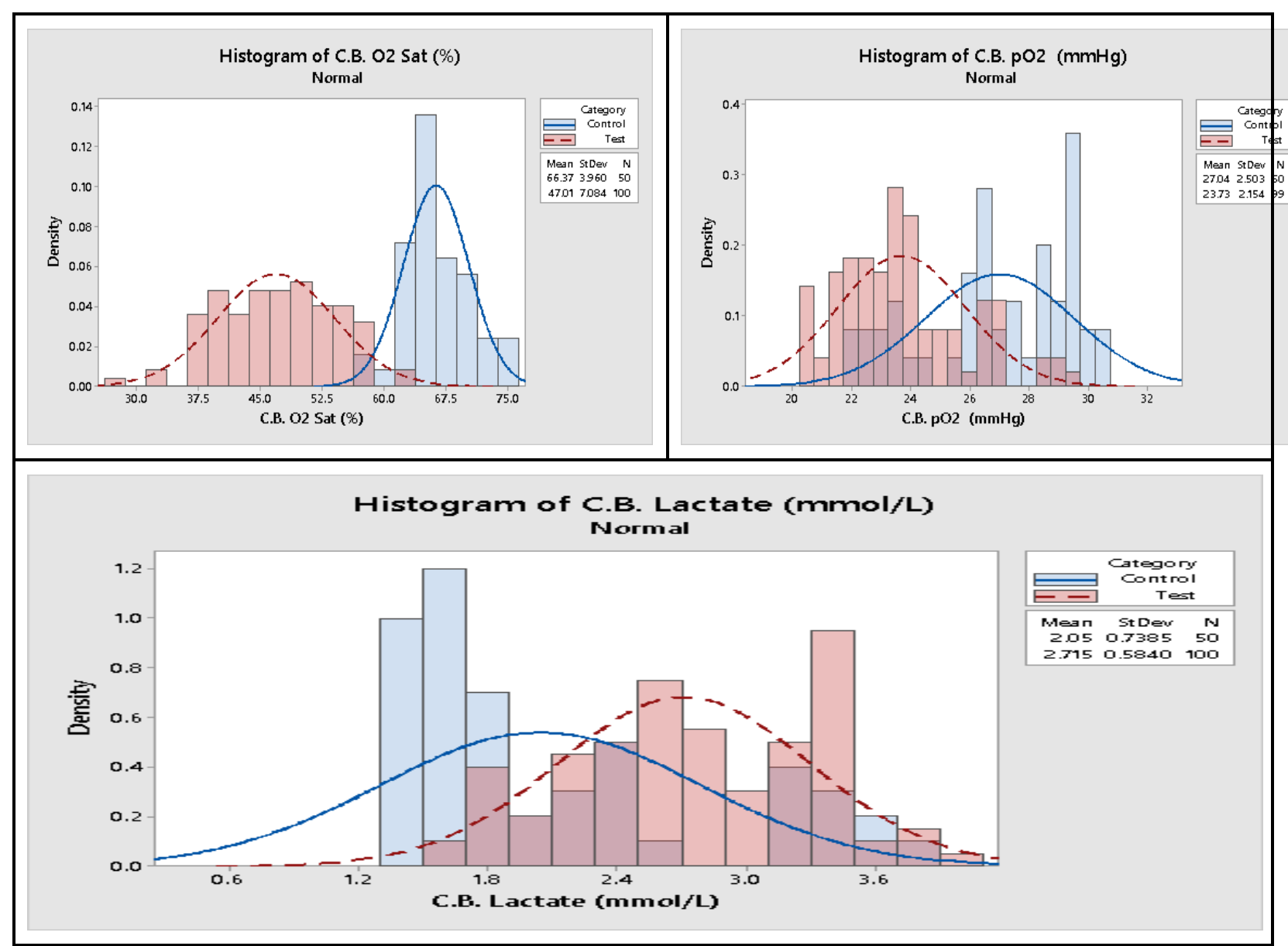

Fig. 1: Respiratory gases, acid-base balance in normal (control) and GDM (test)

There is a significant change in haemoglobin, $\mathrm{RBC}$ count, total WBC count, MCV and MCHC in GDM when compared to healthy population (Table 2). But no significant change was noted in lymphocyte, monocyte, eosinophil, neutrophil, HCT and MCHC of test population compared to the normal group.

Table 02: Distribution of blood indices between the test and control groups

\begin{tabular}{|l|c|c|c|c|}
\hline Parameters & Control $(\mathbf{n}=\mathbf{5 0})$ & Test $(\mathbf{n = 1 0 0})$ & $\mathbf{t}$ & $\mathbf{p}$ \\
\hline $\mathrm{M} . \mathrm{Hb}(\mathrm{g} / \mathrm{dL})$ & $11.86 \pm 0.99$ & $11.6 \pm 0.5$ & 2.134 & $<0.05^{*}$ \\
\hline M. RBC $(\mathrm{K} / \mu \mathrm{L})$ & $4.78 \pm 0.42$ & $4.94 \pm 0.41$ & -2.142 & $<0.05^{*}$ \\
\hline M.WBC $(\mathrm{Cells} / \mu \mathrm{L})$ & $7386 \pm 1873.55$ & $8217 \pm 1258.11$ & -3.219 & $<0.01^{* *}$ \\
\hline M. lymphocyte (\%) & $36.32 \pm 4.75$ & $35.38 \pm 5.33$ & 1.055 & 0.293 \\
\hline M. monocyte (\%) & $4.02 \pm 1.25$ & $4.14 \pm 1.44$ & -0.503 & 0.616 \\
\hline M. eosinophil (\%) & $3.66 \pm 1.14$ & $3.52 \pm 1.34$ & 0.634 & 0.527 \\
\hline M. neutrophil (\%) & $56 \pm 4.42$ & $56.96 \pm 5.11$ & -1.133 & 0.259 \\
\hline M.HCT (\%) & $35.52 \pm 3.16$ & $34.98 \pm 1.79$ & 1.328 & 0.186 \\
\hline M. MCV (fL) & $74.74 \pm 8.69$ & $71.37 \pm 7.13$ & 2.532 & $<0.05^{*}$ \\
\hline M. MCH (pg) & $24.95 \pm 2.73$ & $23.72 \pm 2.3$ & 2.891 & $<0.01^{* *}$ \\
\hline M. MCHC (\%) & $33.42 \pm 0.79$ & $33.25 \pm 0.84$ & 1.204 & 0.23 \\
\hline A.Vas & & & \\
\hline
\end{tabular}

All Values are mean \pm Standard Deviation. $\mathrm{n}=$ Total Number of subjects. The statistical test used t-test. *Significant at $\mathrm{p}<0.05$ and ** Significant at $\mathrm{p}<0.01$. 


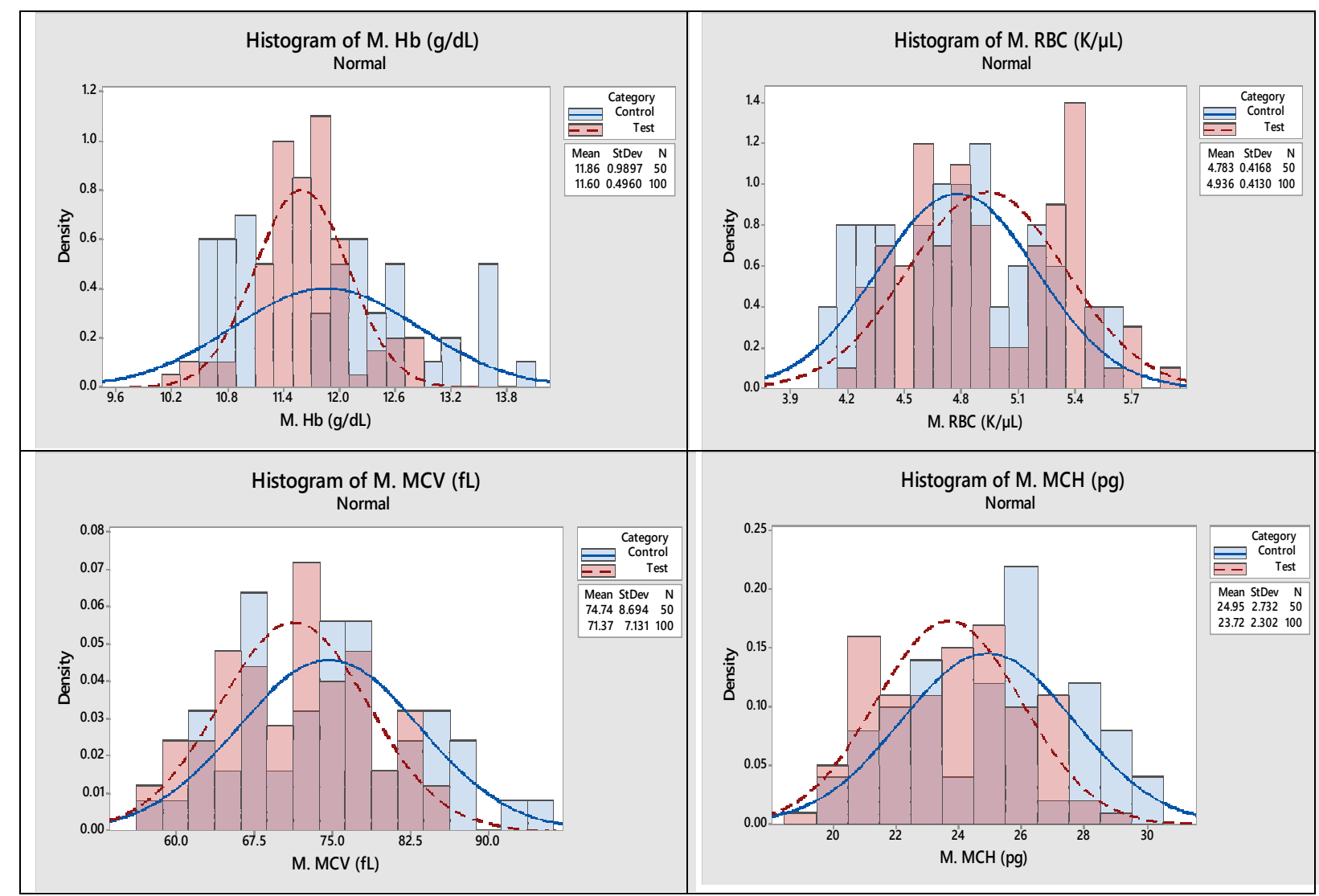

Fig. 2: Haematology parameters in normal (control) and GDM (test)

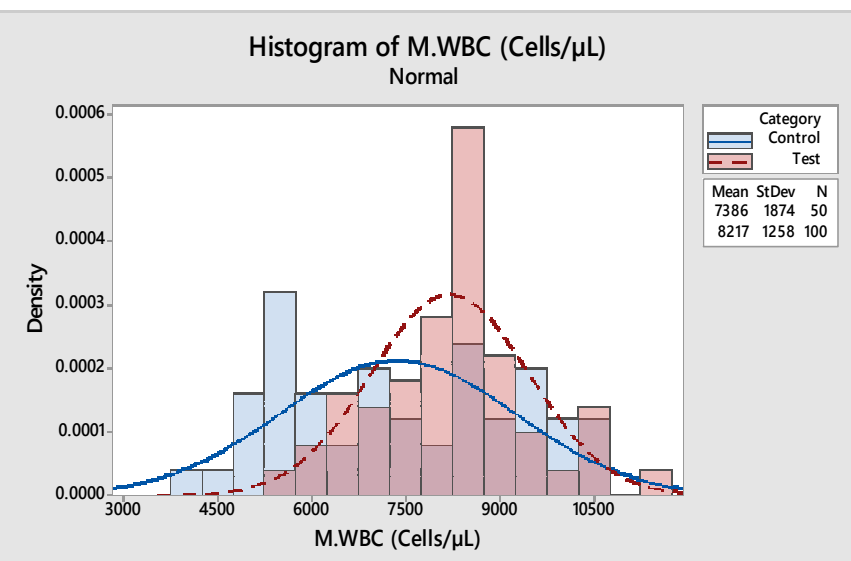

Fig. 3: White blood cell count in normal (control) and GDM (test).

The correlation of birth weight with cord blood gas and cord blood haematological parameters were tested to find the role of GDM on the birth weight of infants
(Table 3). The data showed a significant negative correlation between cord blood $\mathrm{Hb}$ values and cord blood PCV and. pO2 levels with the birth weight of infants.

Table 3: Correlationof birth weight with blood gas and haematological parameters

\begin{tabular}{|l|c|}
\hline Parameters & Birth weight $($ Kg) \\
\hline C.B. $\mathrm{pH}$ & $-0.071(0.387)$ \\
\hline C.B. $\mathrm{pCO} 2(\mathrm{mmHg})$ & $-0.051(0.535)$ \\
\hline C.B. $\mathrm{pO} 2(\mathrm{mmHg})$ & $-.179^{*}(<0.05)$ \\
\hline C.B. O2 Sat $(\%)$ & $-0.146(0.074)$ \\
\hline C.B. Lactate $(\mathrm{mmol} / \mathrm{L})$ & $0.047(0.564)$ \\
\hline
\end{tabular}




\begin{tabular}{|l|c|}
\hline C.B. $\mathrm{Hb}(\mathrm{g} / \mathrm{dL})$ & $-.245^{* *}(<0.01)$ \\
\hline C. B. PCV $(\%)$ & $-.222^{* *}(<0.01)$ \\
\hline C.B. RBC $(\mathrm{K} / \mu \mathrm{L})$ & $0.015(0.858)$ \\
\hline C.B. MCV $(\mathrm{fL})$ & $-0.134(0.102)$ \\
\hline C.B. MCH $(\mathrm{pg})$ & $-0.146(0.074)$ \\
\hline C.B. MCHC $(\%)$ & $-0.049(0.552)$ \\
\hline $\begin{array}{l}\text { Statistics used are the Pearson correlation. All values are the correlation coefficient }(\mathrm{r}) \text { and } \\
\text { significance level }(\mathrm{p}) . * * \text { Correlation is significant at } \mathrm{p}<0.01 \text { level and * Correlation is } \\
\text { significant at }<<0.05 \text { level }\end{array}$ \\
\hline
\end{tabular}

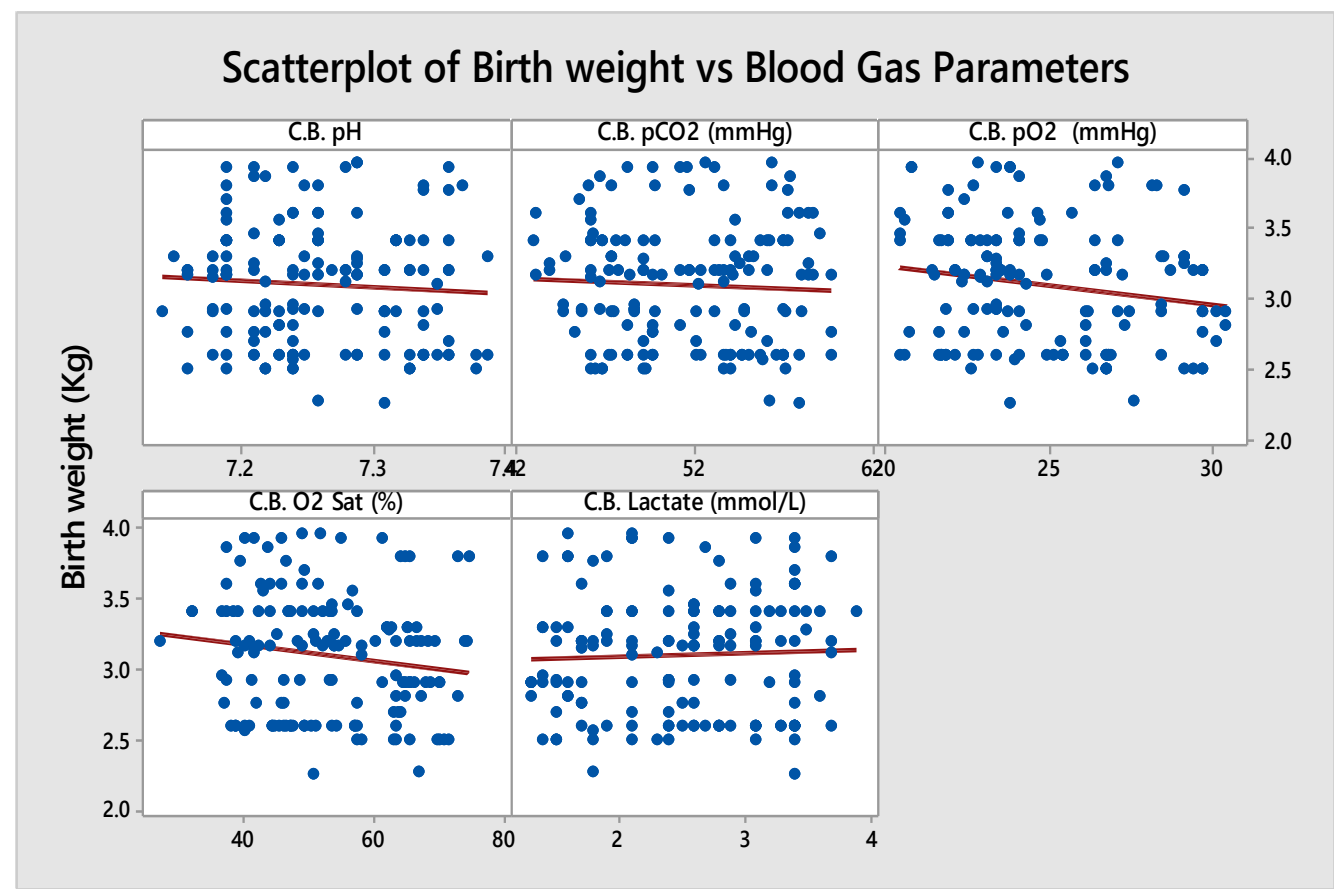

Fig. 4: Scatterplot of the birth weight vs blood gas parameters

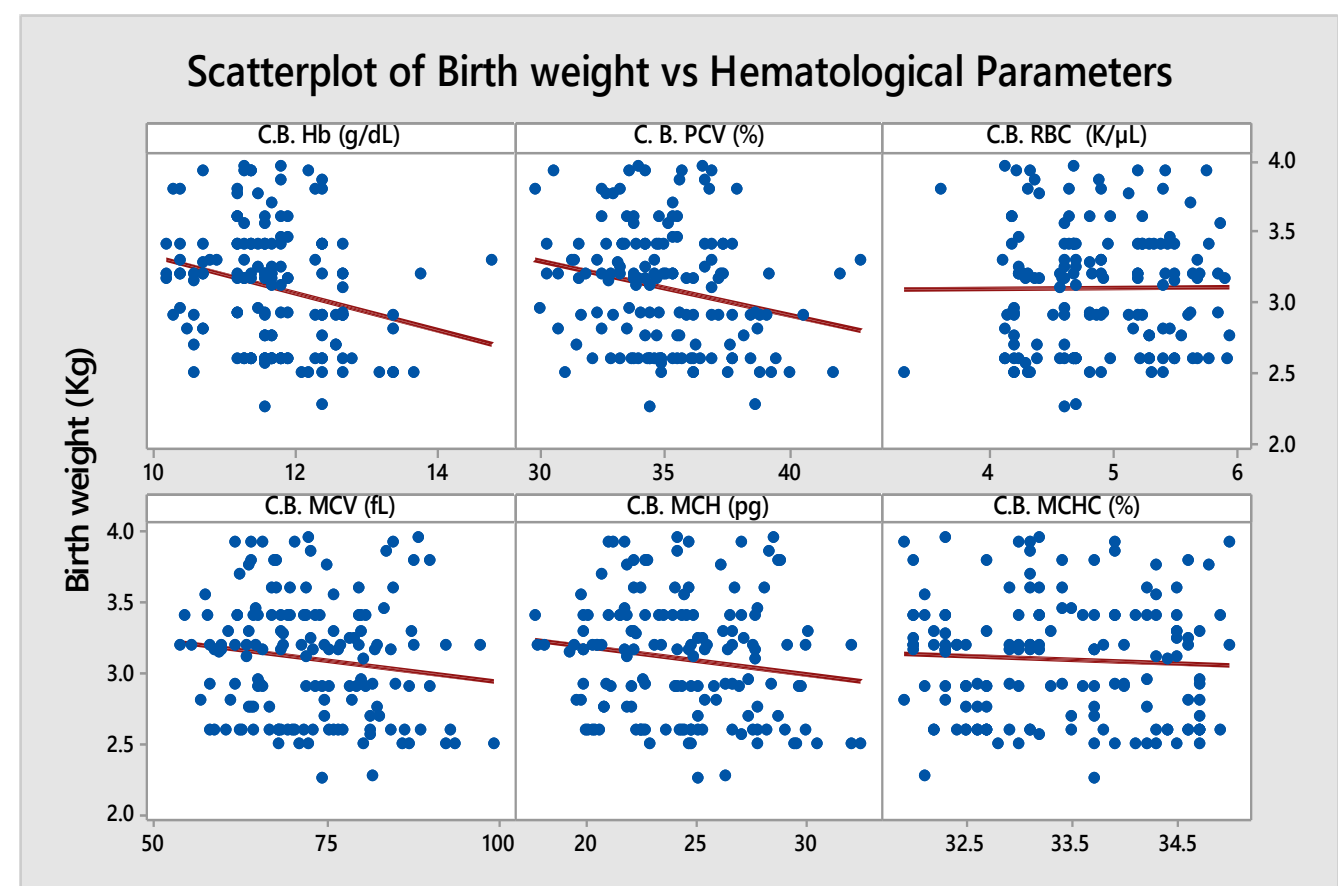

Fig. 5: Scatterplot of the birth weight vs hematological parameters 


\section{Discussion}

Gestational diabetes mellitus (GDM) is a severe and neglected threat to maternal and child health. Many women with GDM experience pregnancy-related complications including high blood pressure, large birth weight babies and obstructed labor. Approximately half of women with a history of GDM go on to develop type 2 diabetes within five to ten years after delivery. It is approximated that 4 million women are affected by GDM in India at any given point in time. ${ }^{7}$ According to the study conducted at Tertiary Health Centre in Northern India by Dahiya $\mathrm{K}$, et al. regarding the maternal and fetal outcome in Gestational Diabetes Mellitus were polyhydramnios and the increased rate of caesarean sections. Babies born to GDM mothers had a higher incidence of metabolic complications and macrosomia. $^{8}$

Pinnock $\mathrm{C}$ et al. reported that the placenta is bound for the transfer of oxygen and carbon dioxide to and from the developing fetus. Oxygen partial pressure gradient between maternal blood in the intervillous space and fetal blood in the umbilical arteries is culpable for the oxygen transfer. Carbon dioxide also crosses the placenta readily by passive diffusion. ${ }^{9}$ The current study results showed that the offspring of gestational diabetic mothers present significant differences in $\mathrm{pO} 2$ and $\mathrm{pCO} 2$ when compared to normal fetuses at delivery. A study conducted by Jahromi BN et al. observed the neonatal umbilical artery blood gas values between offspring of the diabetic mothers and normal mothers which showed higher $\mathrm{pCO} 2$ values in the neonates of the diabetic mothers when compared with the control group. ${ }^{10}$ These changes are the crucial and important evidence that prove the occurrence of foetal hypoxia in GDM cases. Lower oxygen saturation and oxygen content and increased level of lactate concentration were found in GDM neonates when compared to the foetus of normal mothers. Hiden U, et al. Suggested that in diabetes, as a result of the hyper vascularization gross placental structure may be altered. ${ }^{11}$ A potential reduction of placental oxygen transport may result due to greater placental capillary surfaces. Reduced oxygen transport from the placenta and further impaired oxygen delivery may result, due to the reduction of uteroplacental blood flow in diabetic pregnancies especially when maternal hyperglycaemia is more pronounced. GDM fetus accommodates to the hyperglycemia in the utero-environment by developing insulin production, which consequently leads to fetal hyperinsulinemia. ${ }^{12}$

Increasing of lactate concentration occurs because of the initiation of anaerobic glycolysis due to hypoxia. It has since become extensively preferred that umbilical cord blood gas analysis can present significant data about the past, current and the prospective condition of the infant. The haemoglobin levels in GDM mothers' showed decreased value. West JB sighted that umbilical cord blood gas analysis can give an intimation of prior fetal hypoxic stress. ${ }^{13}$ These findings are strengthened by the results of the study conducted by Molnar et al. ${ }^{14}$ They also showed a marked decrease in oxygen content, oxygen saturation and a significant increase in lactate concentrations. Lower oxygen saturation and oxygen content and increased lactate concentrations in offspring of GDM mothers indeed emulate intensified fetal metabolism as an outcome of hyperglycaemia and hyperinsulinemia, and therefore these fetuses demand constant supervision at term and during delivery. Belai et al. conducted the study of cord blood $\mathrm{pH}, \mathrm{pO} 2$ and pCO2 in high-risk pregnancies including gestational diabetes using umbilical arterial cord blood analysis. ${ }^{15}$ Significant association of umbilical cord arterial blood gas $\mathrm{pH}, \mathrm{pO} 2$ and $\mathrm{pCO} 2$ values and the adverse neonatal outcome was found.

Our study shows a striking decrease in haemoglobin, RBC count, and $\mathrm{MCH}$ in GDM when compared to normal, but the change in MCV, MCHC value was not significantly different compared to the normal. This was comparable to the study conducted by Mercelina et al., who found an indicative reduction in cord blood Hemoglobin, Red blood corpuscles, Packed cell volume, Blood indices in the infants of gestational diabetic mothers. ${ }^{16}$ The results were also suggesting a correlation of cord blood $\mathrm{Hb}$, cord blood PCV and Cord blood pO2 with the birth weight of infants. In addition to this, the current study also evaluated the correlation between birth weight and biochemical parameters such as cord blood $\mathrm{Hb}, \mathrm{C} . \mathrm{B}$. pH, $\mathrm{PCO} 2, \mathrm{PO} 2, \mathrm{O} 2$ sat, lactate, $\mathrm{RBC}, \mathrm{MCV}, \mathrm{MCH}, \mathrm{PCV}$ and MCHC, We observed a statistically negative correlation of body weight with $\mathrm{PCV}, \mathrm{Hb}$ and $\mathrm{PO} 2$ and there was no correlation observed with other parameters. A similar observation was obtained in Anne Vambergue et al. and Metzger $\mathrm{BE}$ et al. ${ }^{17,18}$ These studies have observed a negative correlation of these parameters with body weight. The result indicates that the body weight and fetal $\mathrm{Hb}$, partial pressure of oxygen and Packed cell volume have some direct relationship.

\section{Conclusion}

No suggestive changes were found in $\mathrm{pH}$ of GDM neonates when compared to the normal foetus $(\mathrm{N})$. GDM offspring, when compared to the normal, showed a significant decrease in $\mathrm{pO} 2$ and $\mathrm{pCO} 2$. A relative reduction in $\mathrm{O} 2$ saturation and $\mathrm{O} 2$ content in GDM foetus when compared to a normal foetus. The present study indicates that lactate level is significantly increased in GDM neonates when compared to the control group. There is a striking change in haemoglobin, RBC count, total WBC count, MCV and $\mathrm{MCH}$ in GDM when compared to the normal group.

\section{References}

1. Jarmuzek P, Wielgos M, Bomba-Opon DA. Placental pathologic changes in gestational diabetes mellitus. Neuro Endocrinology Letters. 2015;36(2:101-105. 
2. Mahalakshmi MM, Bhavadharini B, Kumar M, Anjana RM, Shah SS, Bridgette A, Choudhury M, Henderson M, Desborough L, Viswanathan M, Ranjani H. Clinical profile, outcomes, and progression to type 2 diabetes among Indian women with gestational diabetes mellitus seen at a diabetes center in south India. Indian journal of endocrinology and metabolism. 2014;18(3):400.

3. Mitanchez D, Yzydorczyk C, Siddeek B, Boubred F, Benahmed M, Simeoni U. The offspring of the diabetic mother-short-and long-term implications. Best Practice \& Research Clinical Obstetrics \&Gynaecology. 2015;29(2):256-69.

4. Desoye G, van Poppel M. The feto-placental dialogue and diabesity. Best Practice \& Research Clinical Obstetrics \&Gynaecology. 2015;29(1):15-23.

5. Dixon BJ, Reis C, Ho WM, Tang J, Zhang JH. Neuroprotective strategies after neonatal hypoxic ischemic encephalopathy. International journal of molecular sciences. 2015;16(9):22368-401.

6. Omo-Aghoja L. Maternal and fetal Acid-base chemistry: a major determinant of perinatal outcome. Annals of medical and health sciences research. 2014;4(1):8-17.

7. DeSisto CL, Kim SY, Sharma AJ. Peer Reviewed: Prevalence Estimates of Gestational Diabetes Mellitus in the United States, Pregnancy Risk Assessment Monitoring System (PRAMS), 2007-2010. Preventing chronic disease. 2014;11.

8. Dahiya K, Sahu J, Dahiya A. Maternal and Fetal Outcome in Gestational Diabetes Mellitus-A Study at Tertiary Health Centre in Northern India. Open Access Library Journal. 2014;1(03):1.

9. Griffiths SK, Campbell JP. Placental structure, function and drug transfer. Continuing Education in Anaesthesia, Critical Care \& Pain. 2015;15(2):84-9.

10. Jahromi BN, Ahmadi N, Cohan N, Jahromi MR. Comparison of the umbilical artery blood gas, nucleated red blood cell, C-reactive protein, and white blood cell differential counts between neonates of diabetic and nondiabetic mothers. Taiwanese Journal of Obstetrics and Gynecology. 2011;50(3):301-5.

11. Hiden U, Desoye G. Insulin and the Placenta in GDM. In Gestational diabetes during and after pregnancy 2010 (pp. 97-111). Springer London.
12. Lappas M, Hiden U, Desoye G, Froehlich J, Mouzon SH, Jawerbaum A. The role of oxidative stress in the pathophysiology of gestational diabetes mellitus. Antioxidants \& redox signaling. 2011;15(12):3061-100.

13. West JB. Thoughts on the pulmonary blood-gas barrier. American Journal of Physiology-Lung Cellular and Molecular Physiology. 2003;285(3):L501-13.

14. Molnár A. Examinations of placental three-dimensional power Doppler indices in pregnancies complicated by diabetes mellitus and intrauterine growth restriction (Doctoral dissertation, szte).

15. Belai YI, Goodwin TM, Durand M, Greenspoon JS, Paul $\mathrm{RH}$, Walther FJ. Umbilical arteriovenous PO2 and PCO2 differences and neonatal morbidity in term infants with severe acidosis. American journal of obstetrics and gynecology. 1998;178(1):13-9.

16. Mercelina-Roumans PE, Breukers RB, Ubachs JM, Van Wersch JW. Hematological variables in cord blood of neonates of smoking and nonsmoking mothers. Journal of clinical epidemiology. 1996;49(4):449-54.

17. Metzger BE, Gabbe SG, Persson B, Buchanan TA, Catalano PA, Damm P, Dyer AR, Leiva A, Hod M, Kitzmiler JL, et al. International association of diabetes and pregnancy study groups recommendations on the diagnosis and classification of hyperglycemia in pregnancy. Diabetes Care. 2010;33:676-682.

18. Vambergue Anne, and Isabelle Fajardy. "Consequences of Gestational and Pregestational Diabetes on Placental Function and Birth Weight." World Journal of Diabetes. (2011;2(11):196-203.

How to cite this article: Augustine G, Sreedharan R, Sampson U, Jithesh T.K, Manikumar R. Evaluation of umbilical cord arterial blood gas analysis in gestational diabetes mellitus. Indian $\mathbf{J}$ Clin Anat Physiol. 2018;5(4):508-514. 